\title{
HUBUNGAN DUKUNGAN KELUARGA DENGAN RESILIENSI CAREGIVER SKIZOFRENIA DI WILAYAH KERJA PUSKESMAS POIGAR DAN PUSKESMAS ONGKAW
}

\author{
Yessica Christy Riany Pesik ${ }^{1}$, Ralph B. J. Kairupan ${ }^{2}$, Andi Buanasari ${ }^{3}$ \\ ${ }^{1,3}$ Program Studi Ilmu Keperawatan Fakultas Kedokteran Universitas Sam Ratulangi \\ ${ }^{2}$ Program Studi Pendidikan Kedokteran , Fakultas Kedokteran , Universitas Sam Ratulangi \\ Email : pesikjessica@gmail.com
}

\begin{abstract}
Family support is important factor in creating a resilience in the effort to treat schizophrenia patients. The purpose of this study is to investigate the relationship between family support with the resilience of schizophrenic caregivers in the work area of Poigar Health Center and Ongkaw Health Center. This study used quantitative study with cross sectional approach, The sample was taken using non-probability techniques, purposive sampling. This studyinvolved 52 respondents from both Health Care Centre. The results of the study showed the level of strength (closeness) between variabels is moderate (0.285), positive direction, and significant $(p=0.041<\alpha=0.05)$. This study concluded there as a moderate, positive and significant relationship between family support (28.5\%) with caregiver resilience. Suggestions, for health centers to further improve the quality of health services for families of schizophrenic patients such as, consultation services, family-related counseling such as adaptation with schizophrenic sufferers, coping with stress and family resources and efforts to overcome stigma.
\end{abstract}

Keywords: Family Support; Caregiver Resilience; Schizophrenia

\begin{abstract}
Abstrak: Dukungan keluarga adalah faktor penting dalam menciptakan ketahanan dalam upaya untuk merawat pasien skizofrenia. Tujuan dari penelitian ini adalah untuk mengetahui dan membuktikan hubungan antara dukungan keluarga dengan resiliensi caregiver skizofrenia di wilayah kerja Puskesmas Poigar dan Puskesmas Ongkaw. Metode penelitian yang digunakan adalah studi kuantitatif dengan pendekatan cross sectional, analisis data memnggunakan teknik korelasi Rank Spearman. Sampel diambil dengan menggunakan teknik non-probabilitas. Jumlah sampel adalah 52 responden dari kedua puskesmas. Hasil penelitian menunjukkan tingkat kekuatan (kedekatan) antara variabel sedang $(0,285)$, arah positif, dan signifikan ( $\mathrm{p}=0,041<\alpha=0,05)$. Kesimpulan: ada hubungan yang moderat, positif dan signifikan antara dukungan keluarga $(28,5 \%)$ dengan resiliensi caregiver. Saran, bagi pusat kesehatan untuk lebih meningkatkan kualitas layanan kesehatan untuk keluarga pasien skizofrenia seperti, layanan konsultasi, konseling terkait keluarga seperti adaptasi dengan penderita skizofrenia, mengatasi stres dan sumber daya keluarga dan upaya untuk mengatasi stigma.
\end{abstract}

Kata Kunci : Dukungan Keluarga; Resiliensi Caregiver; Skizofrenia 


\section{PENDAHULUAN}

Orang Dengan Gangguan Jiwa (ODGJ) adalah orang yang mengalami gangguan dalam pikiran, perilaku, dan perasaan yang termanifestasi dalam bentuk sekumpulan gejala dan/atau perubahan perilaku yang bermakna, serta dapat menimbulkan penderitaan dan hambatan dalam menjalankan fungsi orang sebagai manusia (Kemenkes, 2018). Skizofrenia merupakan keadaan dimana berbagai pemikiran tidak saling berhubungan secara logis, persepsi dan perhatian yang keliru, afek datar dan gangguan aktivitas motorik yang bizzare /perilaku yang aneh (Davinson, 2010). Menurut data yang diperoleh WHO tahun 2019 bahwa sebanyak 20 juta orang di dunia terkena skizofrenia. Prevalensi data skizofrenia di Indonesia meningkat dari 1,7\% menjadi 6,7\% dari tahun 2013 yang awalnya 400 ribu orang menjadi dari 450 ribu orang. Dan untuk di Sulawesi Utara terjadi peningkatan penderita skizofrenia dari 1\% menjadi 7\% (Riskesdas, 2018).

Penderita skizofrenia dianggap berbahaya, bodoh dan aneh serta tidak dapat disembuhkan. Ini yang membuat penderita skizofrenia tidak dibawah ke dokter melainkan dibawa ke dukun atau disembunyikan (Lestari \& Wardhani, 2014). Perasaan takut mendapatkan stigma negatif dari orang-orang terdekat seringkali menjadi stresor tersendiri bagi keluarga penderita skizofrenia (Suhron, 2017). Stress dan tekanan yang dialami keluarga dapat diatasi dengan adanya resiliensi dalam keluarga yang merawat anggota dengan skizofrenia (Zausniewski, 2010).

Resiliensi keluarga (caregiver) meliputi kemampuan untuk mengatasi kesengsaraan dengan tidak hanya bertahan dengan beban yang ada untuk merawat anggota keluarga yang mengalami gangguan mental namun memiliki ketrampilan interpersonal yang adaptif, misalnya adanya penerimaan secara mutual dan keterlibatan yang empatik dari keluarga serta maju berkembang dan bertumbuh lebih kuat dan sehat (Heru \& Dreary, 2011). Efek resiliensi pada anggota keluarga caregiver, menemukan bahwa proses adaptasi, pemulihan, serta resiliensi personal pada kebanyakan $(83 \%)$ pasangan hidup penderita gangguan jiwa adalah factor utama untuk memfasilitasi perubahan positif (Zauszniewski, Bekhet, \& Suresky, 2010). Factor-faktor di atas inilah yang dapat menghambat resiliensi keluarga penderita gangguan mental. Namun jika keluarga cukup tangguh dan mampu melewati factor-faktor di atas, maka resiliensi dapat terbentuk dengan baik (Zauszniewski, 2010).

Resiliensi keluarga juga dipengaruhi oleh dukungan keluarga. Penelitian mengenai dukungan sosial keluarga dengan resiliensi keluarga penderita skizofrenia mayoritas ada pada kategori mendukung, didapati 56 responden dengan presentase $(55,4 \%)$. Hal ini menunjukan bahwa dukungan keluarga merupakan salah satu indikasi yang mempengaruhi resiliensi keluarga itu sendiri (Rahmawati, 2018).

Studi pendahuluan dilakukan pada sepuluh orang caregiver yang berada di wilayah kerja Puskesmas Poigar dan Puskesmas Ongkaw, didapati ada delapan orang caregiver yang mengatakan kurang mendapat dukungan dari orang-orang terdekat seperti keluarga besar seringkali merasa malu, tertekan dan bahkan stress ketika orang-orang terdekat memberikan stigma negative dan menjauhi keluarga karena anggota keluarga yang menderita gangguan jiwa.

Penelitian mengenai resiliensi keluarga itu penting karena mampu mengontrol pola pikir dan pola perilaku keluarga dalam merawat anggota keluarga dengan skizofrenia. Penelitian mengenai resiliensi keluarga sudah pernah dilakukan dengan menggunakan variabel dukungan sosial sebagai variable independen. Dan yang digunakan dalam penelitian ini peneliti memakai dukungan keluarga yang mempengaruhi resiliensi.

Maka peneliti tertarik untuk meneliti hubungan dukungan keluarga dan regulasi emosi dengan resiliensi caregiver 
skizofrenia di wilayah kerja Puskesmas Poigar dan Puskesmas Ongkaw.

\section{METODE PENELITIAN}

Jenis penelitian ini adalah penelitian bersifat analitik korelasi dengan pendekatan cross sectional study, untuk mengetahui hubungan antara dukungan keluarga dan regulasi emosi dengan resiliensi caregiver skizofrenia di wilayah kerja Puskesmas Poigar dan Puskesmas Ongkaw. Penelitian ini telah dilakukan pada bulan Mei-Juni 2020. Populasi pada penelitian ini ialah caregiver skizofrenia di wilayah kerja Puskesmas Poigar dan Puskesmas Ongkaw berjumlah 60 orang. Sampel penelitian sebanyak 22 orang di Puskesmas Poigar dan 30 orang di Puskesmas Ongkaw yang memenuhi kriteria bersedia menjadi responden, memiliki rentang usia 17-60 tahun, tidak memiliki gangguan jiwa, tinggal serumah dengan penderita skizofrenia, serta bisa membaca dan menulis. Instrument dalam penelitian ini menggunakan kuisioner dalam bentuk google form dan kuesioner print out. Untuk dukungan keluarga menggunakan Perceived Social Support-Family Scale (PSS-Fa) yang terdiri dari terdapat 20 pertanyaan dengan pernyataan favourable apabila jawaban "ya" skor 3, jawaban "tidak" skor 2, jawaban "tidak tahu" skor 1. Dan untuk pernyataan unfavourable apabila jawaban "ya" skor 2, jawaban "tidak" skor 3, jawaban "tidak tahu" skor 1. Kuesioner regulasi emosi menggunakan Emotion Regulation Questionaire (ERQ) yang memiliki 10 pertanyaan dengan alternatif jawaban, yaitu: mengisi angka (1-7) yang sesuai dengan keadaan sebenarnya. Angka 7 menggambarkan keadaan yang sesuai, angka 1 menggambarkan keadaan yang tidak sesuai, dan angka 4 menggambarkan kondisi yang netral. Resiliensi caregiver menggunakan kuesiner Family Resillience Assesment Scale (FRAS) dengan skala likert, yaitu sangat tidak sesuai (STS) skor 1, tidak sesuai (TS) skor 2, sesuai (S) skor 3, dan sangat sesuai (SS) skor 4.
Pengolahan data menggunakan uji korelasi Spearman Rank dan pengambilan data diawali dengan pengisian lembar persetujuan menjadi responden sebelum pengisian kuesioner.

\section{HASIL dan PEMBAHASAN}

\section{A. HASIL}

1. Karakteristik Responden

Tabel 1. Distribusi Frekuensi Menurut Karakteristik Responden

\begin{tabular}{|c|c|c|}
\hline $\begin{array}{l}\text { Karakteristi } \\
\mathbf{k}\end{array}$ & Kategori & $\%$ \\
\hline \multirow[t]{4}{*}{ Usia } & $26-35$ & 19,2 \\
\hline & $36-45$ & 21,2 \\
\hline & $46-55$ & 34,6 \\
\hline & $55-65$ & 25,0 \\
\hline Jenis & Laki-Laki & 42,3 \\
\hline \multirow[t]{2}{*}{ Kelamin } & Perempuan & 57,7 \\
\hline & Perguruan & 1,9 \\
\hline \multirow[t]{4}{*}{ Pendidikan } & Tinggi/Diploma & \\
\hline & SMA & 17,3 \\
\hline & SMP & 30,8 \\
\hline & $\mathrm{SD}$ & 42,3 \\
\hline \multirow[t]{6}{*}{ Pekerjaan } & Tidak Sekolah & 7,7 \\
\hline & PNS & 1,9 \\
\hline & Wiraswasta & 3,8 \\
\hline & Pedagang & 7,7 \\
\hline & Petani & 42,3 \\
\hline & Tidak bekerja & 44,2 \\
\hline \multirow[t]{2}{*}{ Penghasilan } & $<1 \mathrm{Juta} /$ bulan & 92,3 \\
\hline & 1 juta -3 & 7,7 \\
\hline \multirow{2}{*}{$\begin{array}{l}\text { Hubungan } \\
\text { dengan }\end{array}$} & juta/bulan & \\
\hline & Ayah & 5,8 \\
\hline \multirow[t]{4}{*}{ Penderita } & $\mathrm{Ibu}$ & 23,1 \\
\hline & Anak & 9,6 \\
\hline & Kakak/Adik & 23,1 \\
\hline & Paman/Bibi & 9,6 \\
\hline Cara & Lainnya & 28,8 \\
\hline \multirow[t]{2}{*}{ Pembayaran } & Biaya Sendiri & 30,8 \\
\hline & BPJS & 69,2 \\
\hline Total & 52 & 100 \\
\hline
\end{tabular}

Sumber : data Primer, 2020 


\section{Karakteristik Penderita}

Tabel 2 Distribusi Frekuensi Menurut Karakteristik Penderita

\begin{tabular}{lll}
\hline Karakteristik & Kategori & \% \\
\hline Usia & $17-25$ & 5,8 \\
& $26-35$ & 26,9 \\
& $36-45$ & 25,0 \\
& $46-55$ & 26,9 \\
Pendidikan & $56-65$ & 15,4 \\
& SMA & 11,5 \\
& SMP & 28,8 \\
& SD & 51,9 \\
& Tidak & 7,7 \\
Pekeraan & Sekolah & \\
& Pedagang & 3,8 \\
& Petani & 9,6 \\
& Tidak & 80,8 \\
& Bekerja & \\
Lama Sakit & Lainnya & \\
& $<5$ tahun & 5,8 \\
Peyakit Kronis & $>5$ tahun & 88,5 \\
& Hipertensi & 15,4 \\
& Ginjal & 1,9 \\
& TB Paru & 3,8 \\
& Tidak ada & 78,8 \\
\hline Total & 52 & 100 \\
\hline
\end{tabular}

Sumber : data Primer, 2020

\section{Analisa Univariat}

Tabel 3. Distribusi Frekuensi Menurut

Dukungan Keluarga

\begin{tabular}{lll}
\hline $\begin{array}{c}\text { Dukungan } \\
\text { Keluarga }\end{array}$ & N & \% \\
\hline Cukup & 18 & 34,6 \\
Baik & 34 & 65,4 \\
\hline Total & 52 & 100
\end{tabular}

Sumber : data Primer, 2020

Tabel 4. Distribusi Frekuensi Menurut Resiliensi Caregiver

\begin{tabular}{lll}
\hline $\begin{array}{l}\text { Resiliensi } \\
\text { Caregiver }\end{array}$ & N & $\%$ \\
\hline Cukup & 37 & 71,2 \\
Tinggi & 15 & 28,8 \\
\hline Total & 52 & 100
\end{tabular}

Sumber : data Primer, 2020

\section{Analisa Bivariat}

Tabel 5 Analisis Hubungan Dukungan Keluarga dengan Resiliensi

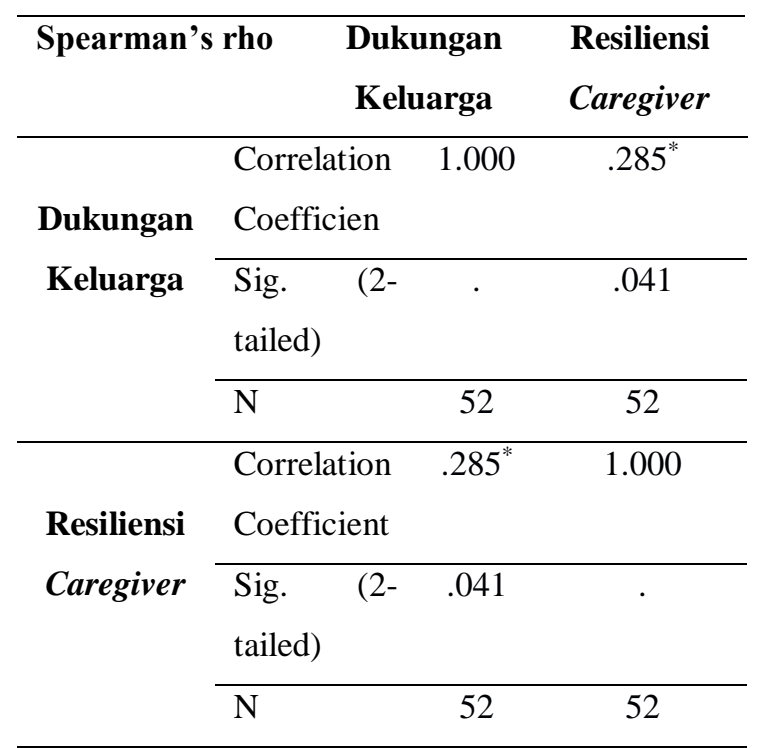

\section{PEMBAHASAN}

Hasil penelitian menunjukan bahwa dari total 52 responden $(100 \%)$ terdapat sebanyak 34 orang $(65,4 \%)$ yang memiliki dukungan keluarga baik dan sebanyak 18 orang $(34,6 \%)$ yang memiliki dukungan keluarga cukup dalam melakukan perawatan pada penderita skizofrenia.. Hal ini dipengaruhi oleh beberapa faktor, seperti lama sakit penderita yang kebanyakan memiliki lama sakit lebih dari lima tahun. Dukungan keluarga merupakan elemen penting dalam melakukan perawatan pada penderita skizofrenia karena dukungan keluarga dapat membantu meningkatkan strategi koping individu dengan strategi-strategi alternatif berdasarkan pengalaman yang berfokus pada aspek-aspek yang positif. Dukungan keluarga membuat keluarga mampu berfungsi dengan berbagai kepandaian dan akal. Sebagai akibatnya, hal ini meningkatkan kesehatan dan adaptasi keluarga. Sehingga dukungan keluarga sangat berpengaruh besar dalam proses penyembuhan, apabila dukungan keluarga tidak ada, maka keberhasilan penyembuhan 
dan pemulihan pasien juga berkurang (Friedman, 2010).

Dari hasil penelitian terkait distribusi frekuensi resiliensi caregiver menunjukan bahwa terdapat 37 orang $(71,2 \%)$ yang memiliki resiliensi caregiver cukup dan sebanyak 15 orang $(28,8 \%)$ memiliki resiliensi caregiver tinggi. Resiliensi caregiver ada pada kategori cukup di pengaruhi oleh faktor pekerjaan responden yang kebanyakan tidak bekerja 23 orang (44,2\%). Menurut Wardaningsih (2007) orang yang tidak bekerja akan memberikan dukungan, dalam bentuk waktu luang yang cukup untuk merawat anggota keluarga dibandingkan dengan keluarga atau responden yang bekerja. Dukungan yang diberikan akan menumbuhkan suatu komunikasi yang baik antar keluarga dan juga suatu keyakinan yang dapat saling diberikan satu sama lain anggota keluarga yang dapat menciptakan resiliensi keluarga yang baik. Resiliensi merupakan proses koping dan adaptasi yang memungkinkan kita memahami suatu proses mediasi stress dan bagaimana mengatasi krisis yang berkepanjangan.

Hasil uji hipotesis yang dilakukan menggunakan uji Spearman Rank dengan tingkat kepercayaan 95\% $(\alpha=0,05)$ menunjukan adanya hubungan yang signifikan antara dukungan keluarga dengan resiliensi caregiver skizofrenia di wilayah kerja Puskesmas Poigar dan Puskesmas Ongkaw dimana nilai $p=0,041$ lebih kecil dari nilai $\alpha=0,05$. Tingkat kekuatan sebesar 0,285 berarti hubungan cukup. Hal ini terjadi karena adanya dukungan keluarga yang cukup seperti karakteristik responden dari segi jenis kelamin, usia, penghasilan perbulan dan lama sakit penderita. Lalu arah hubungan bernilai positif yaitu 0,285 sehingga hubungan kedua variable bersifat searah. Dapat diartikan bahwa jika dukungan keluarga semakin tinggi makan resiliensi keluarga juga semakin tinggi. Hasil penelitian ini didukung oleh Poegoeh (2016) yang menyatakan bahwa resiliensi sangat berhubungan dengan adanya dukungan sosial dalam bentuk dukungan jejaring yang bisa menjadi faktor protektif dalam pembentukan resiliensi keluarga. Dukungan ini bisa diperoleh melalui interaksi dengan keluarga. Kehadiran orang terdekat yaitu keluarga sangat dibutuhkan untuk memberikan dukungan. (Pangastiti, 2011).

\section{KESIMPULAN}

Terdapat hubungan yang signifikan antara dukungan keluarga dengan resiliensi Caregiver Skizofrenia di wilayah kerja Puskesmas Poigar dan Puskesmas Ongkaw. Dimana dukungan keluarga semakin tinggi maka resiliensi keluarga juga semakin tinggi. Implikasi bagi keperawatan dapat menjadi salah satu intervensi keperawatan pada kelurga atau caregiver dalam melakukan perawatan pada penderita skizofrenia.

\section{DAFTAR PUSTAKA}

Adicondro, N., \& Purnamasari, A. (2011). Efikasi Diri, Dukungan Sosial Keluarga Dan Self Regulated Learning Pada Siswa Kelas VIII. Humanitas, 8(1), 17-27. doi: 25986368.

Afriyeni, N \& Subandi. (2015). Kekuatan Keluarga Pada Keluarga Yang Anaknya Mengalami Gangguan Psikosis. Jurnal Psikologi, 11(1), 1931.

Andriani, R. (2017). Efektivitas Pelatihan Regulasi Emosi Untuk Meningkatkan Resiliensi Caregiver Keluarga Pasien Skizofrenia. Jurnal Intervensi Psikologi, 9(2), 254-273.

Davinson, G. \& Neale, J.M. 2010. Psikologi Abnormal. Jakarta: PT Raja Grafindo Persada.

Dewi, K. (2018). Pengalaman Caregiver Dalam Merawat Klien Skizofrenia Di Kota Sungai Penuh. Jurnal 
Endurance. 3(1), 200-212. doi: http://doi.org/10.22216/jen.v3i1.

Friedman, Marilyn M. (2010). Buku Ajar Keperawatan Keluarga: Riset, Teori dan Praktek. Jakarta: EGC.

Hariadi, N., Agustina, D. W., \& Murajani. (2017). Hubungan Antara Sikap Keluarga Dengan Dukungan Keluarga Terhadap Penderita Skizofrenia Di Wilayah Kerja Puskesmas Pekauman Banjarmasin. Jurnal Keperawatan Suaka Insan, 2(1), 1-9.

Heru, A. \& Dreary, L.M. (2011). Developing Family Resilience in Chronic Psychiatric Ilness. Journal of Medicine \& Health, 94(2).

Kementrian Kesehatan. (2018). Laporan Nasional Riset Kesehatan Dasar. Kementrian Kesehatan Republik Indonesia.

Kementrian Kesehatan (2018). UndangUndang No.18 Tahun 2014 Tentang Kesehatan

Jiwa.http://yankes.kemkes.go.id/asse ts/downloads/UU\%20No.\%2018\%20 Th\%202014\%20ttg\%20Kesehatan\% 20Jiwa.pdf

Latipun \& Seferina, F. (2016). Hubungan Dukungan Keluarga Dan Keberfungsian Sosial Pada Pasien Skizofrenia Rawat Jalan. Jurnal Ilmiah Psikologi Terapan, 4(2), 140160 .

Lestari, W. \& Wardhani, Y. F. (2014). Stigma Dan Penanganan Penderita Gangguan Jiwa Berat Yang Di Pasung. Naskah publikasi. Surabaya. Pusat Humaniora, Kebijakan Kesehatan dan Pemberdayaan Masyarakat.

http://eprints.ums.ac.id/71871/2/BA B\%20I.pdf. Diakses pada tanggal 26 Februari 2020.
Livana, PH \& Sujarwo. (2017). Gambaran Penyakit Penyerta Pasien Gangguan Jiwa. Jurnal Keperawatan, 5 (2), 115123.

Magana.SM, García. R. (2007). Psychological Distress Among Latino Family Caregivers of Adults With Schizophrenia: The Roles of Burden and Stigma. Psychiatr Serv. 58(3): 378-384.

Dari

http://www.ncbi.nlm.nih.gov.

Diakses tanggal 21 Juli 2020.

Makmuroch. (2014). Keefektifan Pelatihan Ketrampilan Regulasi Emosi terhadap Penurunan Tingkat Ekspresi Emosi pada Caregiver Pasien Skizofrenia di Rumah Sakit Jiwa Daerah Surakarta. Wacana Jurnal Psikologi. 6(1), 13-34, doi:10.13057/wacana.v6i1.2.

Mastiyas, Y. N. (2017). Hubungan Resiliensi Keluarga Dengan Kekambuhan Pada Orang Dengan Gangguan Jiwa (ODGJ). Skripsi. Universitas Airlangga. http://repository.unair.ac.id/77543/2/ full\%20text.pdf. Diakses tanggal 6 Maret 2020

Nasir, A. \& Muhith, A. (2011). Dasar-dasar Keperawatan Jiwa: Pengantar dan Teori. Jakarta: Salemba Medika.

Notoatmodjo,S. 2012. Metodologi Penelitian Kesehatan. Jakarta: Rineka Cipta.

Nuraenah., Susanti Yossie., \& Putri Eka. (2012). Hubungan Dukungan Keluarga Dan Beban Keluarga Dalam Merawat Anggota Dengan Riwayat Perilaku Kekerasan Di Rs. Jiwa Islam Klender Jakarta Timur 2012. Jurnal Keperawatan Jiwa, 2 (1), 41-50.

Pahlevi, J.R. (2016). Pengaruh Pelatihan Ketrampilan Regulasi Emosi Untuk Meningkatkan Kemampuan Coping 
Stres Orang tua Yang Memiliki Anak Dengan Riwayat Gangguan Skizofrenia. Thesis. Universitas Muhammadiyah Surakarta. http://eprints.ums.ac.id/48105/.

Diakses tanggal 27 Februari 2020.

Poegoeh, D.P. (2016). Peran Dukungan Sosial Dan Regulasi Emosi Terhadap Resiliensi Keluarga Penderita Skizofrenia. Insan, 1(1), 12-21.

PSIK. (2018). Panduan Penulisan Tugas Akhir Mahasiswa. Program Studi Ilmu Keperawatan Fakultas Kedokteran Universitas Sam Ratulangi Manado

Rahmawati, R.E. (2018). Hubungan Dukungan Sosial Dengan Resiliensi Caregiver Penderita Skizofrenia. Jurnal Keperawatan Aisyiyah, 5(1), 71-78. Doi: 2355-6773.

Rukmini, C.T., \& Syafiq, M. (2019). Resiliensi Pada Keluarga Sebagai Caregiver Pasien Skizofrenia Dengan Kekambuhan. Character: Jurnal Penelitian Psikologi, 6(2), 1-8.

Rusnita, \& Syarifuddin. (2019). Dukungan Keluarga pada Klien yang Mengalami Gangguan Jiwa di Wilayah Kerja Puskesmas Ulee Kareng Kota Banda Aceh. Journal of Healthcare Technology and Medicine, 5(1), 118123.

Sharma N, Chakrabarti S, Grover S. (2016). Gender differences in care giving among family - caregivers of people with mental illnesses. World J Psychiatr, 22; 6(1): 7-17 dari http://www.ncbi.nlm.nih.gov.

Diakses tanggal 17 Juli 2020.

Sukmaningpraja, A. \& Santhoso, F. H.

(2016). Peran Regulasi Emosi terhadap Resiliensi pada Siswa Sekolah Berasrama Berbasis Semi Militer. Gadjah Mada Journal Of
Psychology, 2(3), 184-191. doi: 10.22146/gamajop.36944

Stuart, G, W (2013). Prinsip Dan Praktek Keperawatan Dan Kesehatan Jiwa. Edisi Indonesia. Jakarta: Fakultas Keperawatan Indonesia.

Suhron, M. (2017). Effect Psychoeducation Family On Ability Family in Treating People With Mental Disorder (ODGJ) Deprived (Pasung). Journal of Applied Science And Research, 5(1), 41-51. doi: 2348-0416.

Wandasari, W. (2012). Hubungan Antara Resiliensi Keluarga Family Sense Of Coherence Pada Mahasiswa Yang Berasal Dari Keluarga Miskin. Skripsi. Universitas Indonesia. http://lib.ui.ac.id/file?file=digital/203 17251-S-Wenny\%20Wandasari.pdf. Diakses tanggal 17 Juli 2020.

Zauszniewski, J., Bekhet, A. \& Suresky, M.J. (2010). Resilience in Family Members of Person with Serious Mental Illness. Nursing Clinics of North America. 45 (4), 1110-1125, doi: 10.1016/j.cnur.2010.06.007. 